BMJ Open

Sport \&

Exercise

Medicine

\title{
Does dog acquisition improve physical activity, sedentary behaviour and biological markers of cardiometabolic health? Results from a three-arm controlled study
}

\author{
Lauren Powell (D) , ${ }^{1}$ Kate M Edwards, ${ }^{2}$ Adrian Bauman, ${ }^{1}$ Paul McGreevy, ${ }^{3}$ \\ Anthony Podberscek, ${ }^{4}$ Brendon Neilly, ${ }^{5}$ Catherine Sherrington, ${ }^{6}$ \\ Emmanuel Stamatakis ${ }^{1}$
}

\begin{abstract}
To cite: Powell L, Edwards KM, Bauman A, et al. Does dog acquisition improve physical activity, sedentary behaviour and biological markers of cardiometabolic health? Results from a three-arm controlled study. BMJ Open Sport \& Exercise Medicine 2020;6:e000703. doi:10.1136/ bmjsem-2019-000703
\end{abstract}

- Additional material is published online only. To view please visit the journal online (http://dx.doi.org/10.1136/ bmjsem-2019-000703).

Accepted 22 March 2020

Check for updates

(C) Author(s) (or their employer(s)) 2020. Re-use permitted under CC BY-NC. No commercial re-use. See rights and permissions. Published by BMJ.

For numbered affiliations see end of article.

Correspondence to

Lauren Powell;

lauren.powell@sydney.edu.au

\section{ABSTRACT}

Objectives Dog ownership has been associated with improved cardiometabolic risk factors, including physical activity. Most of the evidence originates from crosssectional studies or populations with established disease. This study investigated changes in physical activity and other cardiometabolic risk factors following dog acquisition in a sample of 71 community-dwelling adults.

Methods Participants self-allocated to three groups: 17 individuals acquired a dog within 1 month of baseline (dog acquisition), 29 delayed dog acquisition until study completion (lagged control) and 25 had no interest in dog acquisition (community control). Self-reported and thigh-worn accelerometer-based physical activity patterns, systolic and diastolic blood pressures, resting heart rate and $\mathrm{VO}_{2}$ max were measured three times: baseline, 3 months and 8 months. Data were analysed using repeated measures analysis of covariance with owner age, season, sex and education included as covariates. Post hoc between-group tests were performed where there were significant overall effects $(p<0.05)$

Results We found significant effects in mean daily steps $(F(4,64)=3.02, p=0.02)$ and sit-to-stand transitions $(F(4,66)=3.49, \mathrm{p}=0.01)$. The dog acquisition group performed an additional 2589 steps $(p=0.004)$ and 8.2 sitto-stand transitions $(p=0.03)$ per day at 3 months, although these effects were not maintained at 8 months. We found a significant effect in self-reported weekly walking duration $(F(4,130)=2.84, p=0.03)$ among the lagged control group with an 80 min increase between 3 and 8 months $(p=0.04)$. Other cardiometabolic risk factors were unchanged following dog acquisition.

Conclusion Our study provides encouraging results that suggest a positive influence of dog acquisition on physical activity in the short term but larger and more generalisable controlled studies are needed.

Trial registration number ACTRN12617000967381.

\section{INTRODUCTION}

Cardiovascular disease is the leading cause of global mortality. Many cases could be

\section{Key messages}

New dog owners performed more physical activity within 3 months of acquiring a dog.

- The positive effects of dog acquisition on physical activity patterns were not sustained 8 months after dog acquisition.

- Dog acquisition did not affect measures of blood pressure, resting heart rate or $\mathrm{VO}_{2} \max$

prevented by altering certain lifestyle habits, such as increasing physical activity. ${ }^{1}$ A 2018 pooled analysis found $27.5 \%$ of adults worldwide were insufficiently active. The greatest increase in physical inactivity was documented in high-income Western countries, including Australia, where the prevalence of physical inactivity increased from $32 \%$ to $37 \%$ between 2001 and 2016. ${ }^{2}$

Dog-walking is a lifestyle change with the potential to increase physical activity levels and improve population health. ${ }^{3-5}$ Numerous studies have suggested that dog owners perform more physical activity than nonowners $^{3}{ }^{6-10}$ with meta-analysis supporting these findings. ${ }^{11}$ Across the 29 studies included in the meta-analysis, dog owners reported a median $52 \mathrm{~min}$ more physical activity per week than non-owners which is a sizeable and health-enhancing difference. However, 90\% of the studies were cross sectional ${ }^{11}$ so the direction of causality between dog ownership and physical activity remains unknown. While it is possible that dogs encourage and motivate their owners to perform more physical activity, it is also possible that dog owners are more physically active than non-owners prior to dog acquisition. ${ }^{12}$ To our knowledge, only two studies have investigated the effects of dog 
acquisition on human physical activity patterns and both relied on self-reported measures of physical activity. ${ }^{8}$ Serpell ${ }^{9}$ reported a dramatic increase in the number and duration of leisure-time walks following dog acquisition while Cutt $e t a l^{8}$ reported a smaller, although statistically significant, increase of $48 \mathrm{~min}$ of walking/week among new dog owners.

Dog ownership has been suggested to improve other cardiovascular risk factors, such as blood pressure, by increasing physical activity and decreasing stress reactivity through regular human-dog interactions and enhanced companionship. ${ }^{13}$ Blood pressure is widely used as an indicator of cardiovascular health, with elevated blood pressure usually associated with increased risk of cardiovascular mortality. ${ }^{1415}$ Significant reductions in systolic blood pressure have been documented among individuals with borderline hypertension following dog acquisition ( $\mathrm{ref} 16$, as cited in Levine $e \mathrm{al}^{13}$ ). Much of the research on the potential link between dog ownership and cardiovascular health originates from individuals with established cardiovascular disease. ${ }^{13}$ Among individuals without diagnosed disease, the few cross-sectional studies are inconclusive. Some studies have found that pet owners display lower blood pressure ${ }^{17} 18$ and lower risk of hypertension than non-owners, ${ }^{19}$ while other studies have found no difference ${ }^{20}$ or a negative association between ownership and cardiovascular risk factors. ${ }^{21}$ The effects of dog ownership on aerobic fitness are currently unstudied.

The primary aim of this study was to investigate changes in self-reported and accelerometer-based physical activity patterns following dog acquisition among communitydwelling dog owners. A secondary aim was to examine the influence of dog acquisition on cardiometabolic risk factors, such as blood pressure and cardiorespiratory fitness.

\section{METHODS}

The study methods have been described in detail elsewhere ${ }^{22}$ Briefly, participants self-allocated to one of three groups: imminent dog adopters who were to acquire a dog within 1 month of baseline measures ('dog acquisition'); individuals who were interested in dog ownership but delayed acquisition for the study duration ('lagged control'); and individuals who expressed no interest or plans to acquire a companion dog ('community control'). Data were collected three times: at baseline, 3 months and 8 months. We employed a washout period of 12 months whereby participants must not have owned a dog within the previous year.

\section{Patient and public involvement}

This research was done in consultation with dog welfare organisations and volunteer members of public. Individuals from partner dog welfare organisations were invited to comment on the study design and methods of recruitment. They were not consulted to develop patient-relevant outcomes or interpret the results. The public were not invited to contribute to the writing or editing of this document for readability or accuracy. Patients and/or the public were not involved in the design, or conduct, or reporting, or dissemination plans of this research.

\section{Self-reported walking levels}

Physical activity was reported using the Active Australia Survey, ${ }^{23}$ which has been used extensively in Australia. ${ }^{24-26}$ Participants were asked to report the number of times they had walked for $\geq 10 \mathrm{~min}$ in the week prior to the survey. They were also asked 'What do you estimate was the total time that you spent walking in this way in the last week?' The data were used to quantify the number of bouts of walking/week and the total time spent walking in minutes/week, respectively.

\section{Accelerometer-based physical activity patterns}

Physical activity and sedentary behaviour patterns were also assessed using the ActivPal accelerometer (PAL Technologies, Glasgow, UK) in a subsample of 38 participants ( $n=9$ dog acquisition, $n=16$ lagged control and $n=13$ community control). The ActivPal monitor was applied to participants' right thigh using adhesive tape and worn for a 7 -day period ${ }^{27}$ at baseline, 3 months and 8 months. The monitor was waterproofed so that participants could wear it for the entire 7-day period. The ActivPal provides valid measures of step count, and standing, walking and sedentary time. Importantly, it does not provide participants with any feedback regarding their physical activity patterns. ${ }^{28}{ }^{29}$ ActivPal data were analysed using the Batch processing software (PAL Technologies). We considered data files with a minimum of 3 days of wear time $(\geq 10$ waking hours/day) for inclusion in the analyses.

\section{Blood pressure and resting heart rate}

We used the Omron HEM-7121 automatic blood pressure monitor (Osaka, Japan) to record systolic and diastolic blood pressures and resting heart rate at baseline, 3 months and 8 months using established methods. ${ }^{30}$ Participants sat quietly for $5 \mathrm{~min}$ prior to the measurements to ensure the readings reflected resting values. Three readings were taken at each data collection point, with $30 \mathrm{~s}$ between each reading. The first reading was discarded and the average of the second and third readings was then calculated. In the case that only two readings were taken ( $\mathrm{n}=2 \mathrm{dog}$ acquisition), the first reading was discarded and the second reading was recorded. Machine malfunction or researcher error resulted in four participants with missing data on these outcomes ( $\mathrm{n}=2$ dog acquisition, $\mathrm{n}=1$ lagged control and $n=1$ community control).

\section{$\mathrm{VO}_{2}$ max}

We estimated $\mathrm{VO}_{2}$ max as an indicator of cardiorespiratory fitness ${ }^{31}$ at baseline, 3 months and 8 months. We used the Queens College Step Test ${ }^{32}$ which has acceptable validity and reliability across diverse populations, ${ }^{33}$ including Australian cohorts. ${ }^{34}$ Participants were required to step up and down on a $41.3 \mathrm{~cm}$ wooden block to the beat of a metronome ( 88 beats/min for women or 96 beats/min 
for men) for a 3 min period. The Polar heart rate sensor strap was fitted around the participant's chest and worn for the test duration. Heart rate was recorded for $1 \mathrm{~min}$ after test completion using the Polar M400 watch. $\mathrm{VO}_{2} \max$ was then calculated using the following formulae: 111.33 - $(0.42 \times$ heart rate on step test completion $)$ for males or $65.81-(0.1847 \times$ heart rate on step test completion $)$ for females. ${ }^{35}$ If participants felt uncomfortable at any stage, did not step in time with the metronome or could not physically complete the test, they were instructed to discontinue the test and their data were excluded from analyses. This resulted in 41 participants with valid data ( $\mathrm{n}=10 \operatorname{dog}$ acquisition, $\mathrm{n}=19$ lagged control and $\mathrm{n}=12$ community control participants).

\section{Statistical analysis}

To compare baseline characteristics between the three study groups, we performed a Pearson $\chi^{2}$ test for each categorical variable (gender, alcohol consumption, smoking status, education and season of data collection) and a one-way analysis of variance for each continuous variable (age, total time spent walking, the number of bouts of walking/week, total time spent sedentary per day, systolic blood pressure, diastolic blood pressure, resting heart rate and $\left.\mathrm{VO}_{2} \max \right)$. In the study subsample with accelerometer data, we tested the association between self-reported walking time and accelerometer-based daily walking time using Spearman's correlation. Participants who did not complete all aspects of data collection were excluded from the analyses (online supplementary figure 1). Repeated measures analysis of covariance (ANCOVA) was used to examine changes in physical activity and cardiovascular risk factors across the three study arms. Owner age and sex were included as covariates. The season when baseline data were collected was included as a covariate in all physical activity analyses (self-reported total time spent walking/week, self-reported number of bouts of $\geq 10 \mathrm{~min}$ of walking/week and accelerometerbased number of steps/day). In additional analyses, we also included participants' level of education as a covariate. Post hoc between-group tests were performed where there were significant overall effects $(p<0.05)$. Partial eta squared $\left(\eta_{\mathrm{p}}{ }^{2}\right)$ is presented as a measure of effect size. A $\eta_{\mathrm{p}}{ }^{2}$ of 0.01 is considered a small effect size, 0.09 is considered medium and 0.25 is considered large. ${ }^{36}$ All analyses were conducted in SPSS V.24.

\section{RESULTS}

The baseline characteristics of the study sample are presented in table 1 . Ninety-six participants completed baseline data collection ( $\mathrm{n}=26 \mathrm{dog}$ acquisition, $\mathrm{n}=37$ lagged control, $\mathrm{n}=33$ community control). Twenty-five

Table 1 Baseline characteristics of the study sample by dog ownership status $(n=71)$

\begin{tabular}{|c|c|c|c|}
\hline \multirow[b]{2}{*}{ Baseline characteristics } & \multicolumn{3}{|l|}{ Dog ownership status } \\
\hline & Dog acquisition $(n=17)$ & Lagged control $(n=29)$ & Community control $(n=25)$ \\
\hline Age (years) & $36.9(10.6)$ & $38.0(13.6)$ & $50.7(18.4)$ \\
\hline Gender (female \%) & 100 & 75.9 & 80 \\
\hline \multicolumn{4}{|l|}{ Physical activity } \\
\hline Bouts of $10+$ min of walking/week & $11.5(7.6)$ & $8.3(5.5)$ & $8.9(7.9)$ \\
\hline Minutes spent walking/week* & $303.2(277.7)$ & $219.8(192.4)$ & $251.6(202.7)$ \\
\hline Time spent sedentary (hours/day) ${ }^{\star}$ & $7.7(2.7)$ & $7.8(2.9)$ & $7.4(3.5)$ \\
\hline Resting systolic blood pressure† & $114.4(11.6)$ & $112.6(15.7)$ & $118.1(20.1)$ \\
\hline Resting diastolic blood pressure $†$ & $79.9(9.0)$ & $74.7(8.3)$ & $75.9(9.3)$ \\
\hline Resting heart rate† & $73.4(10.7)$ & $66.5(11.9)$ & $70.3(9.9)$ \\
\hline $\mathrm{VO}_{2} \max \ddagger$ & $37.4(1.6)$ & $43.6(8.2)$ & $39.8(6.6)$ \\
\hline \multicolumn{4}{|l|}{ Alcohol consumption } \\
\hline 1 or more days/week & 70.6 & 55.2 & 56 \\
\hline Less than once per week & 29.4 & 44.8 & 44 \\
\hline \multicolumn{4}{|l|}{ Education§ } \\
\hline Trade certificate/diploma or less (\%) & 47.1 & 17.2 & 12 \\
\hline Bachelor's or postgraduate degree (\%) & 52.9 & 82.8 & 88 \\
\hline Previous dog ownership (\%) & 52.9 & 65.5 & 44 \\
\hline Season of baseline data collection (\% winter) & 58.8 & 86.2 & 92 \\
\hline
\end{tabular}

Data are presented as mean (SD) unless indicated otherwise.

*Based on participant's self-reported physical activity and sedentary behaviour patterns.

†Data available from $n=68$ ( $n=15$ dog acquisition, $n=29$ lagged control, $n=24$ community control).

łBased on submaximal step test. Data available from $n=41$ ( $n=10$ dog acquisition, $n=19$ lagged control, $n=12$ community control).

$\S$ Highest level of education completed. 
participants did not complete all measurements $(n=9 \mathrm{dog}$ acquisition, $n=8$ lagged control, $n=8$ community control) and were excluded from the analyses, leaving 71 participants in the final sample. The reasons for study withdrawal are displayed in online supplementary figure 1 . There were no significant differences in baseline characteristics between participants who did not complete the study and the final sample. ${ }^{22}$ The primary reason for study withdrawal in the dog acquisition group was failure to acquire a $\operatorname{dog}(\mathrm{n}=3)$. In the lagged control and community control groups, the primary reason for dropping out was unknown ( $n=5$ and $n=3$, respectively).

There were no significant differences in baseline characteristics between the dog acquisition, lagged control and community control groups in terms of gender, smoking status, alcohol consumption, total time spent walking, the number of bouts of walking/week or sedentary behaviour patterns. We found no differences between the groups in baseline systolic pressure $(\mathrm{p}=0.45)$ and diastolic blood pressure $(\mathrm{p}=0.16)$, heart rate $(\mathrm{p}=0.11)$ or $\mathrm{VO}_{2} \max$ $(p=0.08)$. There was a significant difference between the groups in the season of data collection $(p=0.01)$, with a higher percentage of participants in the two control groups who underwent baseline measurements in winter compared with the dog acquisition group. There were also statistically significant differences in age, with a mean age of 13.8 years greater in the community control group than dog acquisition group $(\mathrm{p}=0.01)$, and education level, with a greater percentage of individuals who had completed university education in the two control groups $(\mathrm{p}=0.02)$. There were statistically significant correlations between moderate magnitudes between selfreported walking time and accelerometer-based walking time at baseline (Spearman's $\mathrm{r}=0.48, \mathrm{p}=0.002$ ), 3 months (Spearman's r $=0.52, \mathrm{p}=0.001$ ) and 8 months (Spearman's $\mathrm{r}=0.48, \mathrm{p}=0.002)$.

\section{Physical activity and sedentary behaviour}

Self-reported measures of walking

The estimated marginal means (adjusted for age, sex and season) for total time spent walking/week and the number of bouts of $\geq 10 \mathrm{~min}$ of walking/week by dog ownership status are presented in figure 1. Repeated measures ANCOVA showed a statistically significant group-by-time effect for total minutes of walking/week $\left(F(4,130)=2.84, \mathrm{p}=0.03, \eta_{\mathrm{p}}{ }^{2}=0.08\right)$. Post hoc tests revealed the lagged control group displayed an increase of $80 \mathrm{~min}$ of walking/week between 3 and 8 months ( $p=0.04$, 95\% CI 3.86 to 156.97). Compared with baseline, the dog acquisition group performed an additional $93 \mathrm{~min}$ of walking/week at 3 months and $50 \mathrm{~min} /$ week at 8 months, although these findings were not statistically significant $(p>0.26)$. There was no statistically significant difference in the total time spent walking among the community control group.

The group-by-time effect for the number of bouts of $\geq 10 \mathrm{~min}$ of walking/week was $F(4,130)=2.18 \quad(\mathrm{p}=0.08$, $\left.\eta_{\mathrm{p}}{ }^{2}=0.06\right)$. Despite not reaching statistical significance,
Time spent walking/week

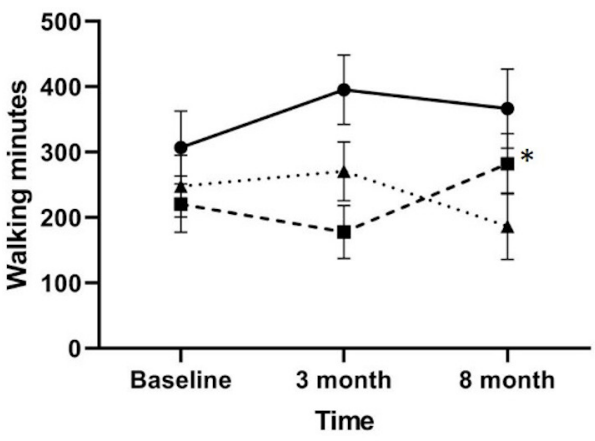

Bouts of $10+$ mins walking/week

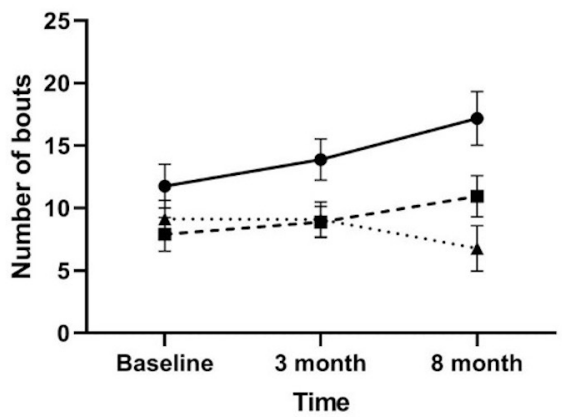

- Dog acquisition (n=17) - - - Lagged control $(n=29) \quad \cdot \mathbf{\Lambda}$. Community control $(n=25)$

Figure 1 Estimated marginal means and the SE of the mean for self-reported walking by dog ownership status, adjusted for age, sex and season $(n=71)$. *Denotes statistical significance $(p<0.05)$.

the dog acquisition and lagged control groups displayed a linear increase in the number of bouts of walking/week between baseline and 8 months (figure 1).

Accelerometer-based measures of physical activity and sedentary behaviour

Repeated measures ANCOVA conducted in the subsample of $\mathrm{n}=38$ participants with accelerometry data revealed a statistically significant group-by-time effect for the number of steps/day $(F(4,64)=3.02, \mathrm{p}=0.02$, $\eta_{\mathrm{p}}{ }^{2}=0.16$ ) (figure 2). Post hoc tests showed the dog acquisition group took an additional 2589 steps/day ( $\mathrm{p}=0.004,95 \%$ CI 1088.13 to 4088.98 ) between baseline and 3 months. Compared with baseline, the dog acquisition group also performed 1396 additional steps/day at 8 months, although this finding did not reach statistical significance $(p=0.17,95 \%$ CI -719.82 to 3512.71$)$. There were no significant differences in the mean number of steps/day in the lagged control $(\mathrm{p}=0.26)$ or community control $(\mathrm{p}=0.90)$ group.

We found a statistically significant group-by-time effect in the mean number of sit-to-stand transitions/ day $\left(F(4,66)=3.49, \mathrm{p}=0.01, \eta_{\mathrm{p}}{ }^{2}=0.18\right)$ (figure 2$)$. The $\operatorname{dog}$ acquisition group made an estimated 8.2 additional sit-tostand transitions/day at 3 months $(\mathrm{p}=0.03,95 \%$ CI 1.36 to 15.08 ), which reduced to 4.6 additional sit-to-stand transitions/day between baseline and 8 months $(\mathrm{p}=0.12$, $95 \%$ CI -1.46 to 10.57 ). Post hoc tests also revealed an 
Daily steps

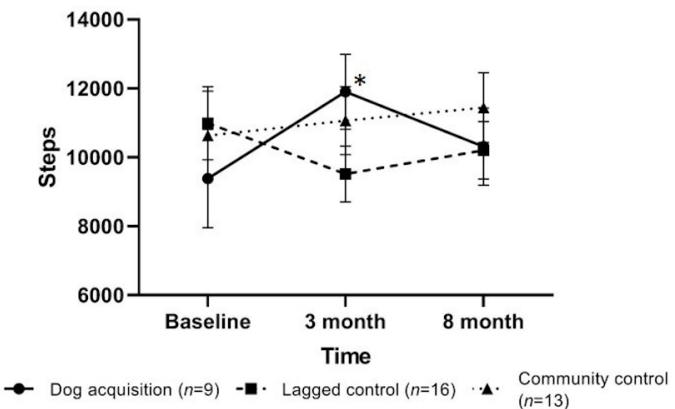

Dog acquisition (n=9) $\quad$-m. Lagged control (n=16) $\quad$ A. ${ }_{(n=13)}^{\text {Commu }}$
Daily sitting time

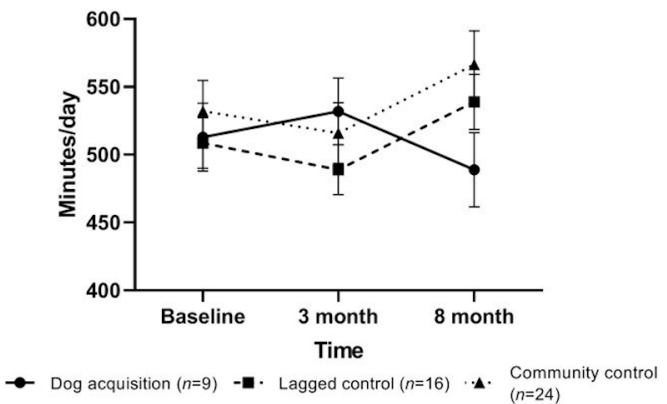

Sit-to-stand transitions

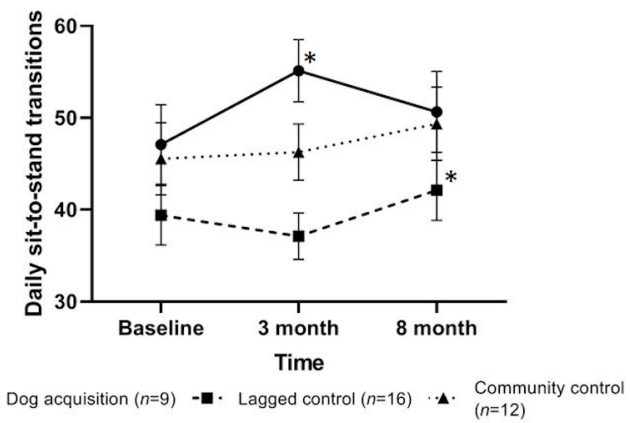

Figure 2 Estimated marginal means and the SE of the mean for accelerometer-based mean daily physical activity and sedentary behaviour amounts and patterns by dog ownership status, adjusted for age, sex and season (daily steps only). *Denotes statistical significance $(p<0.05)$.

increase of 5.4 sit-to-stand transitions/day between 3 and 8 months in the lagged control group ( $\mathrm{p}=0.01,95 \%$ CI 1.58 to 9.30 ). There was no significant difference in the community control group $(\mathrm{p}=0.48)$.

The group-by-time effect for average daily sitting time (min) was $F(4,66)=2.41, \mathrm{p}=0.06, \eta_{\mathrm{p}}{ }^{2}=0.13$ (figure 2). Considering the average daily sitting time in bouts of $\geq 30$ min specifically, the group-by-time effect was not statistically significant $\left(F(4,66)=1.59, \mathrm{p}=0.19, \eta_{\mathrm{p}}{ }^{2}=0.09\right)$.

\section{Cardiometabolic risk factors}

The estimated marginal means (adjusted for age and sex) for systolic blood pressure, diastolic blood pressure, resting heart rate and $\mathrm{VO}_{2}$ max by dog ownership status are presented in figure 3 . We did not find statistically significant group-by-time effects in repeated measures ANCOVA $(\mathrm{n}=68)$ for systolic $(F(4,126)=1.64, \mathrm{p}=0.17$, $\left.\eta_{\mathrm{p}}{ }^{2}=0.05\right)$ or diastolic blood pressure $(F(4,126)=0.89$, $\left.\mathrm{p}=0.47, \eta_{\mathrm{p}}{ }^{2}=0.03\right)$. The group-by-time effect $(\mathrm{n}=68)$ was also not statistically significant for resting heart rate $\left(F(4,126)=0.67, \mathrm{p}=0.61, \eta_{\mathrm{p}}{ }^{2}=0.02\right)$. Repeated measures ANCOVA $(\mathrm{n}=41)$ found no statistically significant group-by-time effects in $\mathrm{VO}_{2} \max (F(4,72)=0.28, \mathrm{p}=0.89$, $\eta_{\mathrm{p}}^{2}=0.02$ ).

\section{Additional adjustment for education}

The results of the repeated measures ANCOVA with additional adjustment for education were not materially different from those of the primary analyses. The group-by-time effect for total time spent walking/week was $F(4,128)=2.55, \mathrm{p}=0.04, \eta_{\mathrm{p}}{ }^{2}=0.07$. The lagged control group displayed an increase of $80 \mathrm{~min}$ reported walking/ week from 3 to 8 months ( $\mathrm{p}=0.04,95 \%$ CI 3.86 to 156.97 ). Considering the number of bouts of $\geq 10$ min of walking/ week, the group-by-time effect was not statistically significant $\left(F(4,128)=1.87, \mathrm{p}=0.12, \eta_{\mathrm{p}}^{2}=0.06\right)$.

In the subsample $(\mathrm{n}=38)$ with accelerometer-based measurements, the group-by-time effect for mean daily steps including adjustment for education was $F(4,62)=2.98, \mathrm{p}=0.03, \eta_{\mathrm{p}}{ }^{2}=0.16$. Post hoc tests mirrored the results of the primary analyses, with the dog acquisition group displaying a significant increase in daily steps at 3 months ( $\mathrm{p}=0.004,95 \%$ CI 1088.13 to 4088.98 ). For mean daily sit-to-stand transitions, the group-by-time effect was also significant $\left(F(4,64)=3.29, \mathrm{p}=0.02, \eta_{\mathrm{p}}{ }^{2}=0.17\right)$. Again, the dog acquisition group performed significantly more sit-to-stand transitions at 3 months $(\mathrm{p}=0.03,95 \%$ CI 1.36 to 15.08$)$ and the lagged control group displayed an increase between 3 and 8 months $(\mathrm{p}=0.01,95 \%$ CI 1.58 to 9.30$)$. The group-by-time effects for mean daily sitting time $\left(F(4,64)=2.23, \mathrm{p}=0.08, \eta_{\mathrm{p}}{ }^{2}=0.12\right)$ and mean daily sitting time in $\geq 30$ min bouts $(F(4,64)=1.59, \mathrm{p}=0.19$, $\left.\eta_{\mathrm{p}}{ }^{2}=0.09\right)$ were not statistically significant.

${ }^{\mathrm{p}}$ We did not find statistically significant group-by-time effects for any cardiometabolic risk factors: systolic blood pressure $\left(F(4,124)=1.43, \quad \mathrm{p}=0.23, \quad \eta_{\mathrm{p}}{ }^{2}=0.04\right)$; diastolic blood pressure $\left(F(4,124)=0.88, \mathrm{p}=0.48, \eta_{\mathrm{p}}{ }^{2}=0.03\right)$; resting heart rate $\left(F(4,124)=0.56, \mathrm{p}=0.69, \eta_{\mathrm{p}}{ }^{2}=0.02\right)$; and $\mathrm{VO}_{2} \max$ $\left(F(4,70)=0.20, \mathrm{p}=0.94, \eta_{\mathrm{p}}{ }^{2}=0.01\right)$. 
Systolic blood pressure

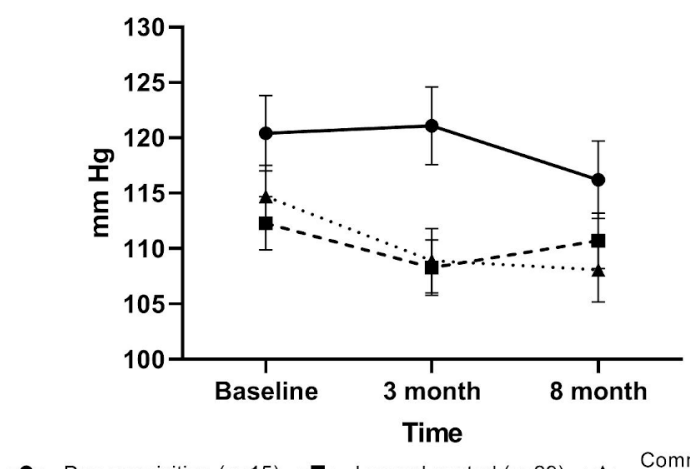

Dog acquisition $(n=15)$
Time

- $\mathbf{a} \cdot$ Lagged control $(n=29)$
Diastolic blood pressure

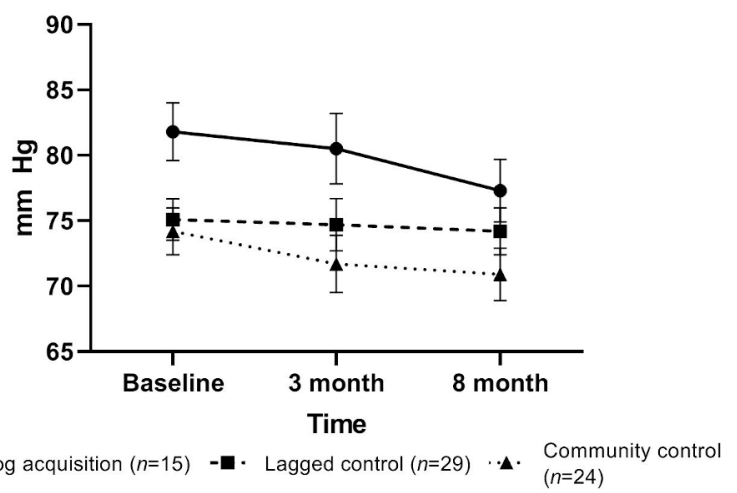

Resting heart rate

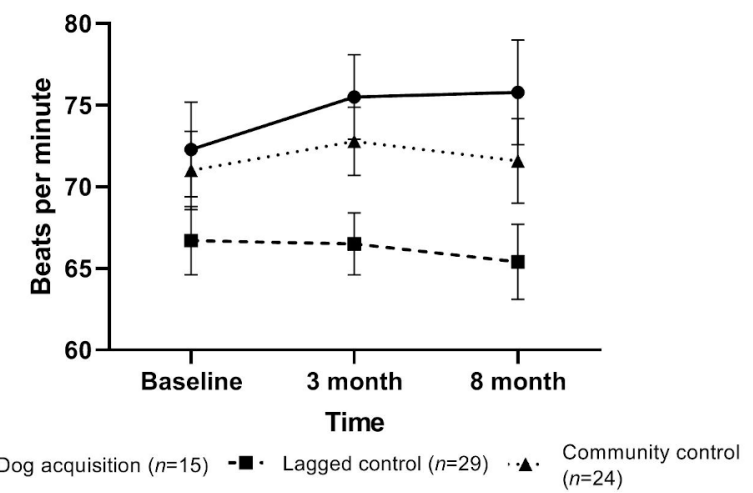

VO2 max

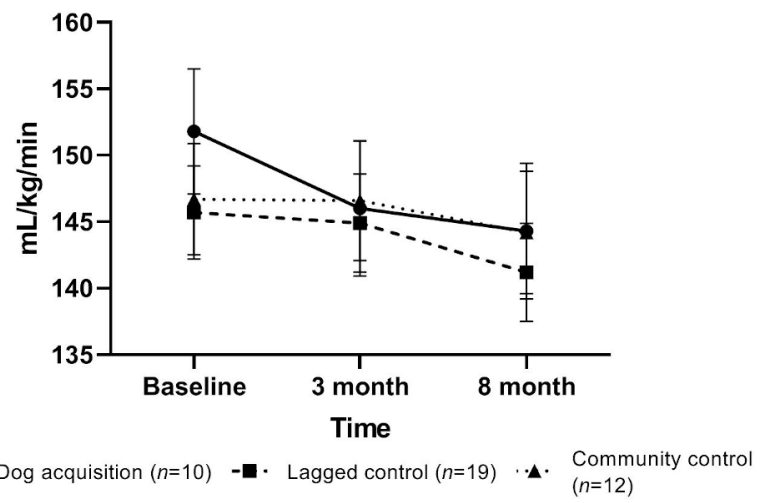

Figure 3 Estimated marginal means and the SE of the mean for cardiometabolic risk factors by dog ownership status, adjusted for age and sex.

\section{DISCUSSION}

This is the first controlled study to investigate accelerometry and self-reported physical activity patterns and cardiometabolic risk factors following dog acquisition. We found evidence that dog acquisition improves objectively measured physical activity and sedentary behaviour patterns within the first few months of dog ownership. Biological measurements of cardiometabolic risk factors were not materially different following dog acquisition.

\section{Physical activity and sedentary behaviour}

Considering self-reported physical activity patterns, we did not find a significant difference in total weekly duration of walking following dog acquisition. The number of bouts of walking/week was also not significantly different despite the linear increase observed in both the dog acquisition and lagged control groups. Although our findings did not reach statistical significance, the increase in physical activity among dog owners could be considered clinically significant. The WHO physical activity guidelines suggest adults should perform a minimum of $150 \mathrm{~min}$ of moderate-intensity physical activity per week. ${ }^{37}$ In this study, dog owners reported an additional 93 min of walking/week in the first 3 months of $\operatorname{dog}$ acquisition, out of which $50 \mathrm{~min}$ increase was sustained to 8 months. Our results are contrary to those of Serpell ${ }^{9}$ who reported a large increase in the number and duration of recreational walks among dog owners following acquisition. Cutt $e t a l^{8}$ also found a significant increase of $48 \mathrm{~min}$ of additional walking/week among new dog owners. Limited statistical power owing to the small sample size of the dog acquisition group may have made it difficult to detect statistically significant patterns.

Considering the lagged control group, we found a statistically significant increase in self-reported walking of $80 \mathrm{~min} /$ week between 3 and 8 months; a difference that may also be considered clinically significant. No such increases were observed in the community control group. The majority of lagged control participants completed 3 months of data collection in spring and 8 months of data collection in autumn. To reduce the possible influence of the season of data collection on physical activity patterns, we adjusted for season in the statistical analyses. Future investigations are needed with more generalisable samples to understand the possible differences in physical activity patterns between individuals who are interested in dog ownership and those who are not.

An examination of accelerometer-based physical activity in a subsample of 38 participants revealed a significant 
increase in total daily steps and daily sit-to-stand transitions following dog acquisition. Dog owners performed approximately 2500 additional steps/day within 3 months of $d o g$ acquisition although the effect was not maintained at 8 months. A similar pattern was evident for sit-to-stand transitions: there was a significant increase among dog owners at 3 months that did not persist 8 months after dog acquisition. It is plausible that dogs have a positive influence on owner sit-to-stand transitions as they may motivate people to stand up to tend to the dog's needs, such as opening the door or throwing a ball. However, our findings may reflect a short-lived effect in which acquiring a dog improves physical activity and sedentary behaviour patterns over the first few months although the effect may start to wear off over time as owners become accustomed to dog ownership and the novelty reduces. Equally, problems with the behaviour of dogs while exercising may deter less committed owners from walking their dogs. Our results are convergent with a recent pilot trial that found individuals took an additional 553 steps/day within 12 weeks of bringing a foster dog into the home $(n=6) .{ }^{38}$ Recent cross-sectional accelerometerbased physical activity studies demonstrated dog owners performed more physical activity than non-owners. ${ }^{10} 3940$ The lagged control group also increased their daily sit-tostand transitions between 3 and 8-month measurements. As described above, further research is needed to highlight the influence that an interest in dog ownership may have on physical activity patterns.

\section{Cardiometabolic risk factors}

Dog acquisition did not appear to affect systolic or diastolic blood pressure. Our results are at odds with the only comparable study, to our knowledge, that found a significant reduction in systolic blood pressure following dog adoption among individuals with borderline hypertension (ref 16, as cited in Levine et al ${ }^{13}$ ). However, the sample of dog owners in the current study was not specifically composed of individuals with borderline hypertension so their baseline blood pressure values were presumably lower, meaning that further reductions in blood pressure following dog acquisition were less likely to be observed. Cross-sectional epidemiological investigations in Norway ${ }^{18}$ and Australia ${ }^{17}$ have suggested dog owners have lower systolic blood pressures than nonowners.

We did not find evidence of a change in resting heart rate following dog acquisition which may be explained by the modest physical activity changes observed. Despite the absence of similar studies investigating dog acquisition and chronic resting heart rate, our findings do not corroborate the few acute studies in the field. For example, acute human-dog interactions may decrease acute measures of human resting heart rate ${ }^{41}$ and pet owners display significantly lower resting heart rates than non-owners prior to undergoing a stressor test. ${ }^{42} \mathrm{We}$ also found no evidence of a change in cardiorespiratory fitness following dog acquisition.

\section{Study strengths and limitations}

The primary strength of the current study is the use of a longitudinal controlled design including measures of health prior to and following dog acquisition. Only three studies have used a similar design to investigate the effects of $\operatorname{dog}$ acquisition on human physical activity ${ }^{89}$ or cardiometabolic health (ref 16, as cited in Levine $e t$ $a l{ }^{13}$ ). The current study is also benefitted by the use of a comprehensive range of objective measures of physical activity and objectively measured biological markers of cardiometabolic health.

There are also several limitations that affect this study. First, we could not randomise due to the complex nature of dog ownership and the strict timing requirements of our study design, meaning participants self-allocated to their study group which may have introduced several biases including the imbalance between group characteristics, such as age and education. However, we performed additional analyses including adjustment for age and education which did not change the overall results. The preliminary nature of this trial and the small sample size in the dog acquisition group also suggest that our study may not have been adequately powered to detect statistically significant effects in this outcome,${ }^{4344}$ increasing the risk of type II error. ${ }^{45}{ }^{46}$ Further research with larger sample sizes is needed. There were also a number of participants $(n=25)$ who did not complete all aspects of data collection. The baseline characteristics of participants who withdrew from the study did not differ significantly from those who completed the study, ${ }^{22}$ although it is still possible that the loss of participants influenced the results. Finally, the absence of males in the dog acquisition group limits the generalisability of our findings.

\section{CONCLUSIONS}

In conclusion, in this sample of community-dwelling dog owners, dog acquisition significantly increased objectively assessed human physical activity within 3 months, although the effect did not persist 8 months after dog acquisition. We did not find statistically significant differences in other cardiometabolic risk factors following dog acquisition. Our study provides encouraging results that suggest a positive influence of dog acquisition on human physical activity, in the short term. We found no evidence for improved cardiometabolic risk factors. Larger controlled studies are needed to confirm our results.

\section{Author affiliations}

${ }^{1}$ Charles Perkins Centre, Prevention Research Collaboration, Faculty of Medicine and Health, Sydney School of Public Health, University of Sydney, Sydney, New South Wales, Australia

${ }^{2}$ Charles Perkins Centre, Faculty of Health Sciences, University of Sydney, Sydney, New South Wales, Australia

${ }^{3}$ Sydney School of Veterinary Science, University of Sydney, Sydney, New South Wales, Australia

${ }^{4}$ Charles Perkins Centre, Sydney School of Veterinary Science, University of Sydney, Sydney, New South Wales, Australia

${ }^{5}$ Royal Society for the Prevention of Cruelty to Animals (RSPCA), Sydney, New South Wales, Australia 
${ }^{6}$ Institute for Musculoskeletal Health, Faculty of Medicine and Health, Sydney School of Public Health, University of Sydney, Sydney, New South Wales, Australia

Twitter Lauren Powell @LaurenRPowell and Emmanuel Stamatakis @M_ Stamatakis

Acknowledgements We thank the Animal Medicines Australia for their support with in-kind compensation to participants. We thank Vicki Davy and John Bishop from PetRescue (www.petrescue.com.au) for assisting us in recruiting participants through their website.

Contributors ES initiated and designed the study, acquired funding, led the broader research programme and supervised the PAWS pilot study. KME, PM, $A B, C S$ and $A P$ contributed to the study design. LP led the data collection. BN contributed to the acquisition of data. LP cleaned and analysed the data and drafted the manuscript. All authors read and approved the final version of the manuscript before submission.

Funding This research was supported by a research donation provided by Ms Lynne Cattell (University of Sydney grant ID: 183100).

Disclaimer The donor had no involvement in the study design; collection, analysis and interpretation of data; writing of the report or the decision to submit the article for publication.

Competing interests LP is a postdoctoral research fellow who does not currently own a dog, but has owned and fostered dogs for several years; $A B$ is an Emeritus Professor of Public Health (Physical Activity) who owns one dog, but has had two dogs for most of the past three decades; KE is an A/Prof in Exercise Physiology who does not own a dog, but grew up in a dog-owning household; CS is a Professor of Public Health who does not own a dog; BN currently owns a dog and has worked in animal welfare shelters for several years; PMcG is a Professor of Animal Behaviour and Animal Welfare Science who currently owns and has owned owns several dogs in the past. AP is the Editor in Chief of Anthrozoös, a journal specialising on human-animal interaction, who does not own a dog; ES is a Professor of Physical Activity, Lifestyle, and Population Health who owns two rescue dogs.

Patient consent for publication Not required.

Ethics approval Ethical approval was obtained from the University of Sydney Human Research Ethics Committee (2016/921) and the Animal Ethics Committee (2017/1134). The study was registered with the Australian New Zealand Clinical Trials Registry. All participants provided informed written consent

Provenance and peer review Not commissioned; externally peer reviewed.

Data availability statement Data are available upon reasonable request. The data included in this study are available from the last author upon reasonable request.

Open access This is an open access article distributed in accordance with the Creative Commons Attribution Non Commercial (CC BY-NC 4.0) license, which permits others to distribute, remix, adapt, build upon this work non-commercially, and license their derivative works on different terms, provided the original work is properly cited, appropriate credit is given, any changes made indicated, and the use is non-commercial. See: http://creativecommons.org/licenses/by-nc/4.0/.

ORCID iD

Lauren Powell http://orcid.org/0000-0003-3141-5551

\section{REFERENCES}

1 World Health Organization. Global status report on noncommunicable diseases 2014. Geneva, Switzerland: World Health Organization, 2014. Report No.: 9241564857;9789241564854.

2 Guthold R, Stevens GA, Riley LM, et al. Worldwide trends in insufficient physical activity from 2001 to 2016: a pooled analysis of 358 population-based surveys with 1.9 million participants. Lancet Glob Health 2018;6:e1077-86.

3 Bauman AE, Russell SJ, Furber SE, et al. The epidemiology of dog walking: an unmet need for human and canine health. Med J Aust 2001;175:632-4.

4 Christian $\mathrm{H}$, Bauman A, Epping JN, et al. Encouraging dog walking for health promotion and disease prevention. Am J Lifestyle Med 2018;12:233-43.

5 Cutt H, Giles-Corti B, Knuiman M, et al. Dog ownership, health and physical activity: a critical review of the literature. Health Place 2007;13:261-72

6 Cutt H, Giles-Corti B, Knuiman M, et al. Understanding dog owners' increased levels of physical activity: results from RESIDE. Am J Public Health 2008;98:66-9.
7 Brown SG, Rhodes RE. Relationships among dog ownership and leisure-time walking in Western Canadian adults. Am J Prev Med 2006;30:131-6.

8 Cutt HE, Knuiman MW, Giles-Corti B. Does getting a dog increase recreational walking? Int J Behav Nutr Phys Act 2008;5:17.

9 Serpell J. Beneficial effects of pet ownership on some aspects of human health and behaviour. J R Soc Med 1991;84:717-20.

10 Westgarth C, Christley RM, Jewell C, et al. Dog owners are more likely to meet physical activity guidelines than people without a dog: an investigation of the association between dog ownership and physical activity levels in a UK community. Sci Rep 2019;9:5704.

11 Christian HE, Westgarth C, Bauman A, et al. Dog ownership and physical activity: a review of the evidence. J Phys Act Health 2013;10:750-9.

12 Herzog $\mathrm{H}$. The impact of pets on human health and psychological well-being: fact, fiction, or hypothesis? Curr Dir Psychol Sci 2011;20:236-9.

13 Levine GN, Allen K, Braun LT, et al. Pet ownership and cardiovascular risk: a scientific statement from the American heart association. Circulation 2013;127:2353-63.

14 Psaty BM, Furberg CD, Kuller LH, et al. Association between blood pressure level and the risk of myocardial infarction, stroke, and total mortality: the cardiovascular health study. Arch Intern Med 2001;161:1183-92.

15 Bundy JD, Li C, Stuchlik P, et al. Systolic blood pressure reduction and risk of cardiovascular disease and mortality: a systematic review and network meta-analysis. JAMA Cardiol 2017;2:775-81.

16 Allen K. Dog ownership and control of borderline hypertension: a controlled randomized trial. 22nd annual scientific sessions of the Society of behavioral medicine. Seattle, WA, USA, 2001.

17 Anderson WP, Reid CM, Jennings GL. Pet ownership and risk factors for cardiovascular disease. Med J Aust 1992;157:298-301.

18 Enmarker I, Hellzén O, Ekker K, et al. Health in older cat and dog owners: The Nord-Trondelag Health Study (HUNT)-3 study. Scand J Public Health 2012;40:718-24.

19 Lentino C, Visek AJ, McDonnell K, et al. Dog walking is associated with a favorable risk profile independent of moderate to high volume of physical activity. J Phys Act Health 2012;9:414-20.

20 Wright JD, Kritz-Silverstein D, Morton DJ, et al. Pet ownership and blood pressure in old age. Epidemiology 2007;18:613-8.

21 Parslow RA, Jorm AF. Pet ownership and risk factors for cardiovascular disease: another look. Med J Aust 2003;179:466-8.

22 Powell L, Edwards KM, McGreevy P, et al. Companion dog acquisition and mental well-being: a community-based three-arm controlled study. BMC Public Health 2019;19:1428.

23 Australian Institute of Health and Welfare. The active Australia survey: a guide and manual for implementation, analysis and reporting. Australian Institute of health and welfare, 2003.

24 Caceres VdeM, Stocks N, Adams R, et al. Physical activity moderates the deleterious relationship between cardiovascular disease, or its risk factors, and quality of life: findings from two population-based cohort studies in southern Brazil and South Australia. PLoS One 2018;13:e0198769.

25 Brown WJ, Burton NW, Marshall AL, et al. Reliability and validity of a modified self-administered version of the active Australia physical activity survey in a sample of mid-age women. Aust N Z J Public Health 2008;32:535-41.

26 Brown W, Bauman A, Chey T, et al. Comparison of surveys used to measure physical activity. Aust N Z J Public Health 2004;28:128-34.

27 Hamer M, Stamatakis E, Chastin S, et al. Feasibility of measuring sedentary time with thigh worn Accelerometry and sociodemographic correlates: the 1970 British cohort study. SSRN Journal 2019.

28 Sellers C, Dall P, Grant M, et al. Validity and reliability of the activPAL3 for measuring posture and stepping in adults and young people. Gait Posture 2016;43:42-7.

29 Grant PM, Ryan CG, Tigbe WW, et al. The validation of a novel activity monitor in the measurement of posture and motion during everyday activities. Br J Sports Med 2006;40:992-7.

30 Hamer M, Ingle L, Carroll S, et al. Physical activity and cardiovascular mortality risk: possible protective mechanisms? Med Sci Sports Exerc 2012;44:84-8.

31 Stamatakis E, Hamer M, O'Donovan G, et al. A non-exercise testing method for estimating cardiorespiratory fitness: associations with all-cause and cardiovascular mortality in a pooled analysis of eight population-based cohorts. Eur Heart J 2013;34:750-8.

32 McArdle WD, Katch FI, Pechar GS, et al. Reliability and interrelationships between maximal oxygen intake, physical work capacity and step-test scores in college women. Med Sci Sports 1972;4:182-6. 
33 Bennett H, Parfitt G, Davison K, et al. Validity of submaximal step tests to estimate maximal oxygen uptake in healthy adults. Sports Med 2016;46:737-50.

34 Lubans DR, Morgan PJ, Callister R, et al. The relationship between pedometer step counts and estimated VO2Max as determined by a submaximal fitness test in adolescents. Pediatr Exerc Sci 2008;20:273-84.

35 Nabi T, Rafiq N, Qayoom O. Assessment of cardiovascular fitness [VO2 max] among medical students by Queens College step test. Int J Biomed Adv Res 2015;6:418-21.

36 Cohen J. Statistical power analysis for the behavioral sciences. Routledge, 2013.

37 World Health Organization. Physical activity. World Health Organization, 2017. http://www.who.int/mediacentre/factsheets/ fs385/en/

38 Potter K, Teng JE, Masteller B, et al. Examining how dog 'acquisition'affects physical activity and psychosocial well-being: findings from the buddystudy pilot trial. Animals 2019;9:666.

39 Mičková E, Machová K, Dad'ová K, et al. Does dog ownership affect physical activity, sleep, and self-reported health in older adults? Int Environ Res Public Health 2019;16:3355.
40 Wu Y-T, Luben R, Jones A. Dog ownership supports the maintenance of physical activity during poor weather in older English adults: cross-sectional results from the EPIC Norfolk cohort. J Epidemiol Community Health 2017;71:905.

41 Handlin L, Hydbring-Sandberg E, Nilsson A, et al. Short-term interaction between dogs and their owners: effects on oxytocin, cortisol, insulin and heart rate-an exploratory study. Anthrozoös 2011;24:301-15

42 Allen K, Blascovich J, Mendes WB. Cardiovascular reactivity and the presence of pets, friends, and spouses: the truth about cats and dogs. Psychosom Med 2002;64:727-39.

43 Button KS, loannidis JPA, Mokrysz C, et al. Power failure: why small sample size undermines the reliability of neuroscience. Nat Rev Neurosci 2013;14:365-76.

44 loannidis JPA. Why most published research findings are false. PLoS Med 2005;2:e124.

45 Ellis PD. The essential guide to effect sizes: statistical power, metaanalysis, and the interpretation of research results. Cambridge University Press, 2010.

46 Sullivan GM, Feinn R. Using effect size-or why the $P$ value is not enough. J Grad Med Educ 2012;4:279-82. 